\title{
A global snapshot of endourology residency training
}

\author{
Asad Ullah Aslam ${ }^{1,2}$, Joseph Philipraj ${ }^{1,3}$, Sayed Jaffrey ${ }^{1,4}$, Noor Buchholz ${ }^{1}$ \\ ${ }^{1}$ U-merge Ltd. (Urology for emerging countries), London, UK*; \\ ${ }^{2}$ Dept. of Urology, Letterkenny University Hospital, Saolta Healthcare Group, Ireland; \\ ${ }^{3}$ Department of Urology, Mahatma Ghandi Medical College \& Research Institute, Sri Balaji Vidyapeeth, Pondicherry, India; \\ ${ }^{4}$ Dept. of Urology, University College Hospital, Galway Clinic and Bons Secours Hospital, Galway, Ireland. \\ * U-merge Ltd. (Urology for Emerging Countries) is an academic urological platform dedicated to facilitate knowledge transfer in urology on all levels \\ from developed to emerging countries. U-merge Ltd. is registered with the Companies House in London/ UK. www.U-merge.com
}

\begin{abstract}
Summary Background: Urology has become more complex over the last decades with surgical sophisticated technologies such as endoscopy, laparoscopy and robotic surgery. As these minimally invasive methods gain popularity throughout the world, this has led in some countries to a serious training gap as compared to other countries, and between generations of surgeons within national training systems. There is a huge heterogeneity in urological training between countries, whether developed or developing. This paper attempts to shed some light onto global urological training, comparing a significant number of various national systems, and to outline global tendencies in urological training. It will enable interested readers to see where their own system stands in international comparison, and hopefully enable them to identify training needs to achieve global quality standards. Materials \& methods: This is a questionnaire-based assessment which was sent to 240 members of U-merge from 62 countries. In addition, there is ample literature on the requirements of structured training programs and assessments, and we have tried to briefly outline the key points in this paper. Results: We received responses from 32 countries Urology residency training is hugely heterogenous between countries. Only $44 \%$ of nations use a structured training program with assessments. Others use the Halstedian apprenticeship approach. Notably, some developing countries do use modern teaching and assessment methods, whereas some developed countries still use the outmoded apprenticeship model. For the interested reader, results have been tabled in detail, and training systems described country by country.

Conclusions: Our results have shown a huge heterogeneity in quality urology training between countries and within continents. In systems without national structure of training, it can be assumed that such differences exist even between hospitals/ training institutions. There is no doubt in times of globalization with resident and doctor migration and exchanges that training needs structure and standardization. The still huge gap in developing countries to catch up and be able to afford latest surgical and learning technologies need to be addressed with the help of responsible outreach programs.
\end{abstract}

KEY WORDS: Surgical training; Urology; Endourology; Performance assessment; DOPS; Dry lab; Wet lab; Simulator training; Global education.

Submitted 2 March 2020; Accepted 15 March 2020

\section{INTRODUCTION}

An estimated 5 billion people lack access to any surgical care. This despite surgical diseases accounting for 11-
$30 \%$ of the global health care burden (1). This implies an urgent need to quality-train more surgeons in all specialties globally.

Historically, surgical training, and urological training as a surgical sub-specialty as well, followed the Halstedian tradition of defined apprenticeship. This includes basically observation, modelling and graded participation in surgical activities. This model of training is characterized through long working hours, poorly defined training goals, and a lack of focus on research and evidence-based best practice. In this traditional system, assessment and evaluation of the trainees' performance is outmoded, significantly subjective, with standards ill-defined and not uniformly applied (2). The optimal method to monitor and assess trainees, for example in endoscopy, has not been formally determined (3). Urology has become more complex over the last decades with increasing medical and surgical sophisticated technologies such as endoscopy, laparoscopy and robotic surgery. As these minimally invasive methods gain popularity throughout the world, this has led in some countries to a serious training gap as compared to other countries (4), and between generations of surgeons within national training systems. There is a huge heterogeneity in urological training between countries, whether developed or developing $(5,6)$. Most countries have a urological training duration of around 5 years, but this may include rotations in nephrology, pediatric surgery, gynecology, general surgery, anesthesia, pathology and others (4). Numerous recent studies have shown that trainees remain dissatisfied with their training in urology in many countries (7-12). The educational landscape in urology training is changing and adapting to modern learning methods. Globalization of demands and services also means there clearly is a need for a standardized and structured urological training for global use.

This must also include competency-based assessment, certification and re-certification (3). Naturally, these changes are adopted by various countries in various ways and speeds. This has led at the current time to a wide variation of training quality between countries and training systems. U-merge is a urological educational platform. Its members are active in international teaching $\&$ training in many countries globally. Therefore, the authors have seen firsthand huge differences in structures and quality of urological training programs. Programs may vary from the old-

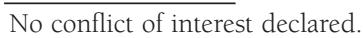


fashioned apprenticeship model with a see one, do one, teach one approach, to highly structured, sometimes nationalized training programs using modern technologies such as virtual, simulated and telemedical training.

This paper attempts to shed some light onto global urological training, comparing a significant number of various national systems, and to outline global tendencies in urological training. We focus on endourology and pediatric endourology training as representative for recent technological changes in urology.

This paper will enable interested readers to see where their own system stands in international comparison, and hopefully enable them to identify training needs to achieve global quality standards.

\section{Materials AND Methods}

This paper is based on a questionnaire which was sent in 2015 to 240 members of U-merge from 62 countries (Appendix 1). U-merge members are consultant level academic urologists in their respective countries.

The questionnaire addressed

- Structure and duration of the urology training program

- Training in basic urology and endourology (if any)

- Sub-specialty training in pediatric urology

- Assessment structure

- Availability of simulated training options.

No funding has been obtained to conduct this study.

\section{RESULTS}

\section{Cumulative results}

Of 240 questionnaires emailed to U-merge members in 60 countries, we received 37 (15.4\%) responses from 32 countries. Twenty-one (56\%) of these have no structured training program. Urology training follows an apprenticeship model. The other 16 have a structured training program. Endourology training can be integrated into the mainstream residency training or have its own defined training period. Duration of training within structured programs varies from 0.5 to 6 years. In 7 (18\%) countries, urology residency training can be completed without gaining competency in endourology. 8 (21\%) do not require URS, 17 (46\%) do not require fURS/RIRS, and 18 (48\%) do not require PCNL competency. $3(8 \%)$ countries require endourology training in children (Table 1).

As per specific endourological procedures, 22 (59\%) of countries require their trainees to be independently competent in URS, 5 (13\%) to be competent with assistance, and $2(5 \%)$ require mere exposure during training. In 10 (27\%) URS training has not been specified.

For fURS/RIRS, the numbers are 9 (24\%), 10 (27\%), 6 $(16 \%)$, and $13(35 \%)$, respectively. For PCNL the numbers are $6(16 \%), 13(35 \%), 9(24 \%)$, and $12(32 \%)$, respectively. For endourological procedures in children, independent competency is usually not required to complete urology residency. 4 (11\%) of countries require

Table 1.

Structured urology training programs and endourology components by country.

\begin{tabular}{|c|c|c|c|c|c|c|c|}
\hline Country & $\begin{array}{l}\text { Structured } \\
\text { endourology } \\
\text { training }\end{array}$ & $\begin{array}{l}\text { Duration endourology } \\
\text { training program } \\
\text { (years) }\end{array}$ & $\begin{array}{l}\text { Completion of training } \\
\text { without competence } \\
\text { in endouro procedures }\end{array}$ & $\begin{array}{l}\text { Completion of training } \\
\text { without competence } \\
\text { in URS }\end{array}$ & $\begin{array}{l}\text { Completion of training } \\
\text { without competence } \\
\text { in fURS/RIRS }\end{array}$ & $\begin{array}{l}\text { Completion of training } \\
\text { without competence } \\
\text { in PCNL }\end{array}$ & $\begin{array}{l}\text { Completion of training } \\
\text { without competence } \\
\text { in EndoUro in Children }\end{array}$ \\
\hline Algeria & No & Not applicable & Yes & No & No & No & Yes \\
\hline Austria & No & Not applicable & Yes & No & No & No & Yes \\
\hline Australia & Yes & 6 & Yes & No & No & No & Yes \\
\hline Bangladesh & No & Not applicable & Yes & Yes & Yes & Yes & Yes \\
\hline Brazil & Yes & 0,5 & Yes & No & Yes & No & Yes \\
\hline Bulgaria & Yes & 1 & Yes & No & No & No & Yes \\
\hline Canada & No & Not applicable & Yes & No & No & Yes & Yes \\
\hline China & No & Not applicable & Yes & No & No & Yes & Yes \\
\hline Colombia & No & Not applicable & Yes & No & Yes & Yes & Yes \\
\hline Egypt & No & Not applicable & Yes & No & Yes & No & Yes \\
\hline El Salvador & No & Not applicable & Yes & Yes & Yes & Yes & Yes \\
\hline France & No & Not applicable & No & No & No & No & Yes \\
\hline Germany & Yes & 5 & Yes & No & Yes & Yes & Yes \\
\hline Greece & No & Not applicable & Yes & No & Yes & Yes & Yes \\
\hline India & Yes & 5 & Yes & No & Yes & Yes & Yes \\
\hline Iran & Yes & 2 & Yes & No & Yes & Yes & Yes \\
\hline 11taly & no & Not applicable & Yes & Yes & Yes & Yes & Yes \\
\hline Kenya & Yes & 4 & Yes & No & No & No & Yes \\
\hline Kurdistan & Yes & 1 & No & No & No & No & Yes \\
\hline Moldova & No & Not applicable & Yes & No & Yes & Yes & Yes \\
\hline Morocco & Yes & 5 & Yes & Yes & Yes & Yes & Yes \\
\hline Nepal & Yes & 3 & No & No & No & No & No \\
\hline Oman & No & Not applicable & Yes & Yes & Yes & Yes & Yes \\
\hline Pakistan & Yes & 6 & Yes & No & No & No & Yes \\
\hline Panama & No & Not applicable & Yes & No & No & № & Yes \\
\hline Romania & No & Not applicable & Yes & No & No & No & Yes \\
\hline Serbia & No & Not applicable & Yes & No & No & Yes & Yes \\
\hline South Africa & No & Not applicable & $\mathrm{N}_{0}$ & No & No & No & No \\
\hline Spain & No & Not applicable & Yes & Yes & Yes & Yes & Yes \\
\hline Sweden & Yes & 5 & Yes & No & No & No & Yes \\
\hline Syria & No & Not applicable & Yes & No & Yes & Yes & Yes \\
\hline Tunisia & Yes & 2 & No & No & No & No & No \\
\hline$\overline{\text { UAE }}$ & No & Not applicable & Yes & Yes & Yes & Yes & Yes \\
\hline$\overline{U K}$ & Yes & 5 & No & No & No & No & Yes \\
\hline
\end{tabular}


Table 2.

Core competencies required in endourology by country.

\begin{tabular}{|c|c|c|c|c|c|c|c|c|c|c|c|c|c|c|c|c|c|c|c|c|}
\hline Country & $\begin{array}{l}\text { URS Perfom } \\
\text { independentity }\end{array}$ & $\begin{array}{l}\text { URS perform } \\
\text { with } \\
\text { assistance }\end{array}$ & $\begin{array}{l}\text { URS } \\
\text { exposure }\end{array}$ & $\begin{array}{l}\text { URS Lwarn } \\
\text { at specialist } \\
\text { fellowship level }\end{array}$ & $\begin{array}{l}\text { URS not } \\
\text { spectifed }\end{array}$ & $\begin{array}{l}\text { fURS/RRS } \\
\text { Perform } \\
\text { independentity }\end{array}$ & $\begin{array}{l}\text { fURS/RIRS } \\
\text { perform vith } \\
\text { assistance }\end{array}$ & $\begin{array}{l}\text { fuRS/RIRS } \\
\text { exposure }\end{array}$ & $\begin{array}{l}\text { fURS/RRRS } \\
\text { Learn at } \\
\text { specialist } \\
\text { fellouship level }\end{array}$ & $\begin{array}{l}\text { fURS/RIRS } \\
\text { not specified }\end{array}$ & $\begin{array}{c}\text { PCNL } \\
\text { Perform } \\
\text { independertity }\end{array}$ & $\begin{array}{l}\text { PCNL perform } \\
\text { with } \\
\text { assistance }\end{array}$ & $\begin{array}{l}\text { PCNL } \\
\text { exposure }\end{array}$ & $\begin{array}{l}\text { PCNL Leam } \\
\text { at specialist } \\
\text { fellowsipip level }\end{array}$ & $\begin{array}{l}\text { PCNL not } \\
\text { specified }\end{array}$ & $\begin{array}{c}\text { Endourol in } \\
\text { children } \\
\text { Perform } \\
\text { independently }\end{array}$ & $\begin{array}{l}\text { Endourol in } \\
\text { children } \\
\text { perform with } \\
\text { assistance }\end{array}$ & $\begin{array}{l}\text { Endourol in } \\
\text { children } \\
\text { exposire }\end{array}$ & $\begin{array}{l}\text { Endourol in } \\
\text { children Learn } \\
\text { at specialist } \\
\text { fellowship level }\end{array}$ & $\begin{array}{l}\text { Endourol in } \\
\text { children } \\
\text { not spectified }\end{array}$ \\
\hline$\overline{\text { Algeria }}$ & Yes & & & & & Yes & & & & & & Yes & & Yes & & & & & & Yes \\
\hline Austria & & & & & Yes & & & & & Yes & & & & & Yes & & & & & Yes \\
\hline Australia & Yes & & & & & Yes & & & & & & Yes & & & & & & & Yes & \\
\hline Bangladesh & & Yes & & & & & & & Yes & & & Yes & & & & & & & Yes & \\
\hline Brazil & Yes & & & & & & & Yes & & & & Yes & & & & & & & & Yes \\
\hline Bulgaria & Yes & & & & & & Yes & & & & & & Yes & & & & & & Yes & \\
\hline Canada & Yes & & & Yes & & Yes & & & Yes & & Yes & & & Yes & & & & & & Yes \\
\hline China & & Yes & & & & & & Yes & & & & & Yes & & & & & & & Yes \\
\hline Colombia & Yes & & & & & & Yes & & & & & Yes & & & & & & & & Yes \\
\hline Egypt & Yes & & & & & & Yes & & & & Yes & & & & & & Yes & & & \\
\hline El Salvador & & & & & Yes & & & & & Yes & & & & & Yes & & & & & Yes \\
\hline France & Yes & & & & & Yes & & & & & Yes & & & & & & & & & Yes \\
\hline Germany & & Yes & & & & & & & & Yes & & & & & Yes & & & & & Yes \\
\hline Greece & & & & & Yes & & & & & Yes & & & & & Yes & & & & & Yes \\
\hline India & Yes & & & & & & Yes & & & & & Yes & & & & & & & & Yes \\
\hline Iran & Yes & & & & & & & & & Yes & & & Yes & & & & & Yes & & \\
\hline Iraq & Yes & & & & & & Yes & Yes & & & & Yes & Yes & Yes & & & Yes & Yes & Yes & \\
\hline Ireland & Yes & & & & & Yes & & & & & & Yes & & & & & & & Yes & \\
\hline$\overline{\text { Italy }}$ & & & & & Yes & & & & & Yes & & & & & Yes & & & & & Yes \\
\hline Kenya & Yes & & & & & Yes & & & & & & Yes & Yes & Yes & & & & & Yes & \\
\hline Kurdistan & Yes & & & & & & Yes & & & & & Yes & & & & & & & & Yes \\
\hline Moldova & Yes & & & & & & & & & Yes & & & & & Yes & & & & & yes \\
\hline Morocco & & & Yes & & & & & Yes & & & & & Yes & & & & & Yes & & \\
\hline$\overline{\text { Nepal }}$ & Yes & Yes & & & & Yes & Yes & & & & Yes & Yes & & & & & & & & Yes \\
\hline \multicolumn{21}{|l|}{$\overline{0 \text { man }}$} \\
\hline Pakistan & Yes & & & & & & Yes & & & & & Yes & & & & & Yes & & & \\
\hline Panama & & & & & Yes & & & & & Yes & & & & & Yes & & & & & Yes \\
\hline Romania & Yes & & & & & & Yes & & & & Yes & & & & & & & & & Yes \\
\hline Serbia & & & & & Yes & & & & & & & & & & Yes & & & & & \\
\hline South Africa & & & & & Yes & & & & & Yes & & & & & Yes & & & & & Yes \\
\hline Spain & & & & & Yes & & & & & Yes & & & & & Yes & & & & & Yes \\
\hline Sweden & Yes & Yes & Yes & & & Yes & Yes & Yes & Yes & & Yes & Yes & Yes & Yes & & & & & & Yes \\
\hline Syria & Yes & & & & & & & & & Yes & & & Yes & & & & Yes & & & \\
\hline Tunisia & Yes & & & & & & & Yes & & & & & & Yes & & & & & & Yes \\
\hline UAE & & & & & Yes & & & & & Yes & & & & & Yes & & & & & Yes \\
\hline$\overline{U K}$ & Yes & & & & & Yes & & & & & & & Yes & & & & & & & Yes \\
\hline Ukraine & & & & & Yes & & & & & Yes & & & & & Yes & & & & & Yes \\
\hline
\end{tabular}

competency with assistance by trainers, and 3 (8\%) require some exposure during training. Some countries offer post-residency training on a fellowship level: 3 (8\%) for fURS/RIRS, 6 (16\%) for PCNL, and 6 (16\%) for pediatric procedures, respectively (Table 2 ). Twenty-one (56\%) countries have defined a minimum procedure number for endourology training: 20 (54\%) for URS, 13 (35\%) for fURS/RIRS, 18 (48\%) for PCNL, and 7 (19\%) for pediatric endourological procedures. Indicative numbers vary widely: 10-450 for URS, 10-100 for fURS/RIRS, 6-250 for PCNL, and 2-300 for pediatric procedures, respectively (Table 3 ). Twenty-six (70\%) countries have no structured performance assessment during training in place. 19 (51\%) rely on a general assessment, 12 (32\%) perform regular audit, 9 (24\%) use examinations as a tool of assessment, and 14 (38\%) apply formal Direct Observation of Procedural Skills (DOPS) (Table 4). Regarding simulated surgical skills training, 7 (19\%) have a "dry lab" facility for URS at their disposal, another 7 (19\%) have a "wet lab" training option for URS. 6 (16\%) have these as a compulsory training part in their programs. Each 6 (16\%) countries offer either for fURS/ RIRS training, and 6 (16\%) offer "dry lab" and 5 (13\%) "wet lab" training for PCNL. Each 3 (8\%) use these as compulsory part of training (Table 5).

\section{Results by country}

As mentioned before, twenty-one (56\%) countries have no structured training program (Figure 1). Urology training follows an apprenticeship model. Another 16 have a structured training program of varying duration and performance assessments (Figure 2). In the following we present a short summary for the urological training in all responder countries in alphabetical order.

The following 21 countries have NO structured training program:

\section{Algeria}

The completion of urological training includes competence in URS (semi-rigid ureteroscopy), fURS/RIRS (flexible ureteroscopy/retrograde intrarenal surgery) and PCNL (percutaneous nephrolithotomy), with exception of endourological procedures in children. Trainees are expected to perform a minimum of 10 cases each of URS and fURS/RIRS. In addition, fifteen PCNL with trainer assistance is a requirement. There is compulsory wet lab training on animal models for URS, fURS/RIRS and PCNL. No structured method of performance assessment has been specified.

\section{Austria}

For endourological procedures (URS, fURS/RIRS, PCNL) a combined minimum case load of 150 procedures is required. There is no specified level of competence for these endourologal procedures in children. There is no 
Table 3.

Minimum endourology procedure numbers required by country.

\begin{tabular}{|c|c|c|c|c|c|c|c|c|c|c|c|}
\hline Country & $\begin{array}{c}\text { Min No. } \\
\text { of case load }\end{array}$ & $\begin{array}{l}\text { URS Min } \\
\text { No. of Case Load }\end{array}$ & $\begin{array}{l}\text { URS indicative } \\
\text { number }\end{array}$ & $\begin{array}{l}\text { fURS/RIRS min no. } \\
\text { of caseload }\end{array}$ & $\begin{array}{c}\text { fURS/RIRS } \\
\text { indicative numbers }\end{array}$ & $\begin{array}{l}\text { PCNL min no. } \\
\text { of caseload }\end{array}$ & $\begin{array}{l}\text { PCNL indicative } \\
\text { numbers }\end{array}$ & $\begin{array}{l}\text { Endourology in chilidren } \\
\text { min no. of caseload }\end{array}$ & $\begin{array}{l}\text { Endourology in children } \\
\text { indicative numbers }\end{array}$ & $\begin{array}{l}\text { All } 4 \text { procedures } \\
\text { combined case numbers }\end{array}$ & $\begin{array}{c}\text { Not } \\
\text { specified }\end{array}$ \\
\hline Algeria & Yes & Yes & 10 & Yes & 10 & Yes & 15 & No & 0 & Not mentioned & \\
\hline Austria & Yes & Yes & Not mentioned & Yes & Not mentioned & Yes & Not mentioned & Yes & Not mentioned & 150 & \\
\hline$\overline{\text { Australia }}$ & Yes & Yes & 100 & Yes & 75 & Yes & 15 & No & 0 & Not mentioned & \\
\hline Bangladesh & No & No & 0 & No & 0 & No & 0 & No & 0 & No & \\
\hline Brazil & Yes & Yes & 12 & No & No & Yes & 6 & No & No & & \\
\hline Bulgaria & Yes & Yes & 50 & Yes & 10 & Yes & 10 & No & No & Not mentioned & \\
\hline Canada & No & No & Not mentioned & No & Not mentioned & No & Not mentioned & № & Not mentioned & Not mentioned & \\
\hline$\overline{\text { Colombia }}$ & № & № & & No & & № & & № & & Not mentioned & \\
\hline Egypt & Yes & Yes & 60 & Yes & 20 & Yes & 30 & Yes & 10 & Not mentioned & \\
\hline$\overline{\text { El Salvador }}$ & No & No & No & No & No & No & No & No & No & Not mentioned & \\
\hline France & No & Yes & 50 & Yes & 50 & Yes & 20 & No & No & Not mentioned & \\
\hline Germany & No & Yes & 50 & No & No & No & No & No & No & Not mentioned & \\
\hline Greece & No & No & No & No & No & № & № & No & No & Not mentioned & \\
\hline India & Yes & Yes & 20 & Yes & 20 & Yes & 5 & Yes & 2 & Not mentioned & \\
\hline Iran & Yes & Yes & 70 & No & No & Yes & 50 & Yes & 10 & Not mentioned & \\
\hline Iraq & Yes & Yes & 450 & Yes & 30 & Yes & 60 & Yes & 300 & Not mentioned & \\
\hline Italy & no & No & & & & & & & & & Yes \\
\hline Kenya & Yes & Yes & 50 & Yes & 50 & Yes & 30 & No & No & Not mentioned & \\
\hline Kurdistan & Yes & Yes & 200 & Yes & 100 & Yes & 250 & Yes & 20 & Not mentioned & \\
\hline Moldova & No & No & & & & & & & & & Yes \\
\hline$\overline{\text { Morocco }}$ & No & No & No & No & No & No & No & No & No & Not mentioned & \\
\hline Nepal & Yes & Yes & 200 & Yes & 25 & Yes & 100 & No & Not mentioned & Not mentioned & \\
\hline Oman & & & & & & & & & & & Yes \\
\hline Pakistan & Yes & Yes & 400 & No & No & Yes & 250 & No & No & Not mentioned & \\
\hline Panama & No & & & & & & & & & & Yes \\
\hline Romania & Yes & Yes & 20 & No & No & Yes & 20 & No & № & Not mentioned & \\
\hline Serbia & Yes & Yes & 50 & No & No & No & No & No & No & Not mentioned & \\
\hline South Africa & No & No & No & No & No & No & No & No & No & Not mentioned & \\
\hline Spain & No & No & No & No & No & № & No & No & No & Not mentioned & \\
\hline Sweden & No & No & No & No & No & No & № & No & No & Not mentioned & \\
\hline Syria & No & No & No & No & No & № & № & No & No & Not mentioned & \\
\hline Tunisia & Yes & Yes & Not mentioned & No & No & Yes & 20 & No & No & Not mentioned & \\
\hline$\overline{\text { UAE }}$ & No & No & & & & & & & & & Yes \\
\hline UK & Yes & Yes & 50 & Yes & 50 & Yes & 10 & Yes & 10 & Not mentioned & \\
\hline Ukraine & No & No & No & No & № & No & № & No & No & Not mentioned & \\
\hline
\end{tabular}

Table 4.

Performance assessments by country.

\begin{tabular}{|c|c|c|c|c|c|c|}
\hline Country & General assessment of performance & Audit & Formal examination/viva & Direct Obs of Procedure Skills (DOPS) & Several of above assessments & No specific assessment \\
\hline Algeria & No & No & No & No & No & Yes \\
\hline Austria & Yes & Yes & Yes & No & Yes & No \\
\hline Australia & Yes & Yes & Yes & Yes & Yes & No \\
\hline Bangladesh & No & No & No & No & No & Yes \\
\hline Brazil & No & No & No & No & No & Yes \\
\hline Bulgaria & Not mentioned & Not mentioned & Not mentioned & Not mentioned & Yes & No \\
\hline Canada & Not mentioned & Not mentioned & Not mentioned & Not mentioned & Yes & No \\
\hline China & No & Yes & No & Yes & Yes & Yes \\
\hline Colombia & Not mentioned & Not mentioned & Not mentioned & Not mentioned & Yes & Yes \\
\hline Egypt & Yes & No & Yes & Yes & Yes & Yes \\
\hline El Salvador & No & No & No & No & No & No \\
\hline France & Yes & Yes & Yes & Yes & Yes & Yes \\
\hline Germany & $\mathrm{N}_{0}$ & No & No & No & No & No \\
\hline Greece & Yes & № & No & Yes & Yes & Yes \\
\hline India & Yes & No & No & No & No & Yes \\
\hline Iran & Yes & Yes & No & Yes & Yes & Yes \\
\hline Iraq & Yes & Yes & Yes & Yes & Yes & Yes \\
\hline Ireland & Yes & Yes & No & Yes & Yes & Yes \\
\hline Kurdistan & Yes & Yes & No & Yes & Yes & Yes \\
\hline Moldova & No & № & No & No & No & $\mathrm{N}_{0}$ \\
\hline Morocco & Yes & No & No & No & No & Yes \\
\hline $\begin{array}{l}\text { Nepal } \\
\end{array}$ & Yes & Yes & Yes & No & Yes & Yes \\
\hline Oman & & & & & & No \\
\hline Pakistan & Yes & Yes & Yes & No & Yes & Yes \\
\hline Panama & $\mathrm{N}_{0}$ & No & No & No & No & $\mathrm{N}_{0}$ \\
\hline Romania & No & No & No & No & No & No \\
\hline Serbia & Yes & No & No & No & № & Yes \\
\hline South Africa & Yes & No & No & Yes & Yes & Yes \\
\hline Spain & No & $\mathrm{N}_{0}$ & No & No & № & No \\
\hline Sweden & No & No & No & Yes & No & Yes \\
\hline Syria & Not mentioned & Not mentioned & Not mentioned & Not mentioned & Yes & Yes \\
\hline Tunisia & Yes & Yes & No & Yes & Yes & Yes \\
\hline \multicolumn{7}{|l|}{ UAE } \\
\hline$\overline{U K}$ & Yes & No & Yes & Yes & Yes & Yes \\
\hline Ukraine & Yes & No & No & No & No & Yes \\
\hline
\end{tabular}


Table 5.

Availability and integration of dry \& wet lab model training into the training program by country.

\begin{tabular}{|c|c|c|c|c|c|c|c|c|c|}
\hline Country & URS Drylab & URS Wettab & URS Compulsory & FURS Drylab & FURS Wetlab & FURS Compulsory & PCNL DryLab & FURS Wetlab & FURS Compulsory \\
\hline Algeria & No & Yes & Yes & No & Yes & Yes & No & Yes & Yes \\
\hline Austria & No & No & № & No & No & No & No & No & № \\
\hline Australia & No & No & No & No & No & No & No & No & No \\
\hline Bangladesh & No & No & No & No & No & No & No & No & NNo \\
\hline Brazil & NS & NS & $\mathrm{N}_{0}$ & NS & NS & No & NS & NS & No \\
\hline Bulgaria & Yes & No & Yes & Yes & No & Yes & Yes & No & № \\
\hline Canada & No & No & № & No & No & No & No & No & № \\
\hline China & Yes & No & No & Yes & Yes & $\mathrm{N}_{0}$ & Yes & Yes & No \\
\hline Egypt & No & No & № & No & No & No & No & No & No \\
\hline El Salvador & No & No & No & No & No & No & No & No & No \\
\hline France & Yes & Yes & No & Yes & Yes & No & Yes & Yes & No \\
\hline Germany & No & Yes & Yes & No & No & No & No & No & No \\
\hline Greece & No & No & No & $N_{0}$ & No & No & $N_{0}$ & No & $\mathrm{N}_{0}$ \\
\hline India & Yes & No & No & Yes & No & No & Yes & No & No \\
\hline Iran & No & № & No & No & No & No & № & No & No \\
\hline Iraq & No & Yes & Yes & No & Yes & Yes & No & Yes & Yes \\
\hline Ireland & No & No & $\mathrm{N}_{0}$ & No & No & No & No & No & No \\
\hline Kurdistan & & & No & & & No & & & No \\
\hline Moldova & No & Yes & Yes & № & No & No & No & No & № \\
\hline Morocco & & & No & & & No & & & No \\
\hline$\overline{\text { Nepal }}$ & No & No & No & No & No & No & No & No & No \\
\hline Oman & & & & & & & & & no info \\
\hline Pakistan & & & No & & & No & & & № \\
\hline Panama & & & No & & & No & & & № \\
\hline Romania & & & No & & & No & & & No \\
\hline Serbia & Yes & Yes & No & Yes & Yes & No & Yes & Yes & No \\
\hline South Africa & No & NNo & № & № & No & No & No & No & No \\
\hline Spain & No & No 0 & No 0 & No & No & No & No & No & No \\
\hline Sweden & Yes & Yes & № & Yes & Yes & No & No & No & № \\
\hline Syria & No & No & № & No & No & No & No & No & No \\
\hline Tunisia & Yes & No & Yes & No & Yes & No & Yes & No & Yes \\
\hline UAE & & & & & & & & & no info \\
\hline$\overline{U K}$ & No & No & No & No & No & No & No & No & No \\
\hline Ukraine & No & No & No & No & No & No & No & No & No \\
\hline
\end{tabular}

compulsory dry or wet lab training. The assessment is via general assessment of performance, audit and formal examination with viva by the trainers.

\section{Bangladesh}

Trainees can achieve completion of training without proven competence in fURS/RIRS, PCNL and endourological surgery in children. They are required to perform some URS and PCNL with trainer assistance.

Endourology in children is later taught at fellowship level. Indicative numbers of procedure and performance assessment methods are not specified.

\section{Canada}

URS and fURS/RIRS are a requirement for completion of training with candidates expected to perform these procedures independently. Endourology in children and PCNL is taught at fellowship level post-residency. Model training is not compulsory. Various method of assessment of performance are in place.

\section{China}

For completion of training, URS with trainer assistance is required. However, trainees are expected to have had exposure to fURS and PCNL. There is no specified endourology training in children. There is dry lab training for URS and wet lab training for fURS and PCNL, albeit not compulsory. Audit and DOPS are used for assessment.

\section{Colombia}

URS is mandatory and trainees are expected to perform it independently. fURS and PCNL with trainer assistance are required. Endourology in children is not regulated. There is no model training and no specific assessment structure in place.

\section{Egypt}

Trainees can complete their training without gaining independent level competence in fURS/RIRS and endourological procedures in children. Twenty and 10 assisted or observed cases in fURS and paediatric endourology, respectively, are indicative, albeit not mandatory. URS and PCNL procedures are compulsory for the trainee to perform independently, with indicative numbers of 60 and 30 , respectively. There is no compulsory model training. Assessment of performance is via formal examination with viva and DOPS.

\section{El Salvador}

There is no specified mandatory requirement for any endourological procedures. Indicative numbers, provision of model training, or assessment methods are not specified.

\section{France}

There is no structured endourology training program. However, it is mandatory to achieve competence in URS, fURS/RIRS and PCNL. Endourological procedures in children is not a mandatory requirement. Fifty cases each for URS and fURS/RIRS, and 20 cases of PCNL are indicative, with numbers unspecified for paediatric endourology. There are dry and wet labs for each of these procedures. However, model training is not compulsory. 

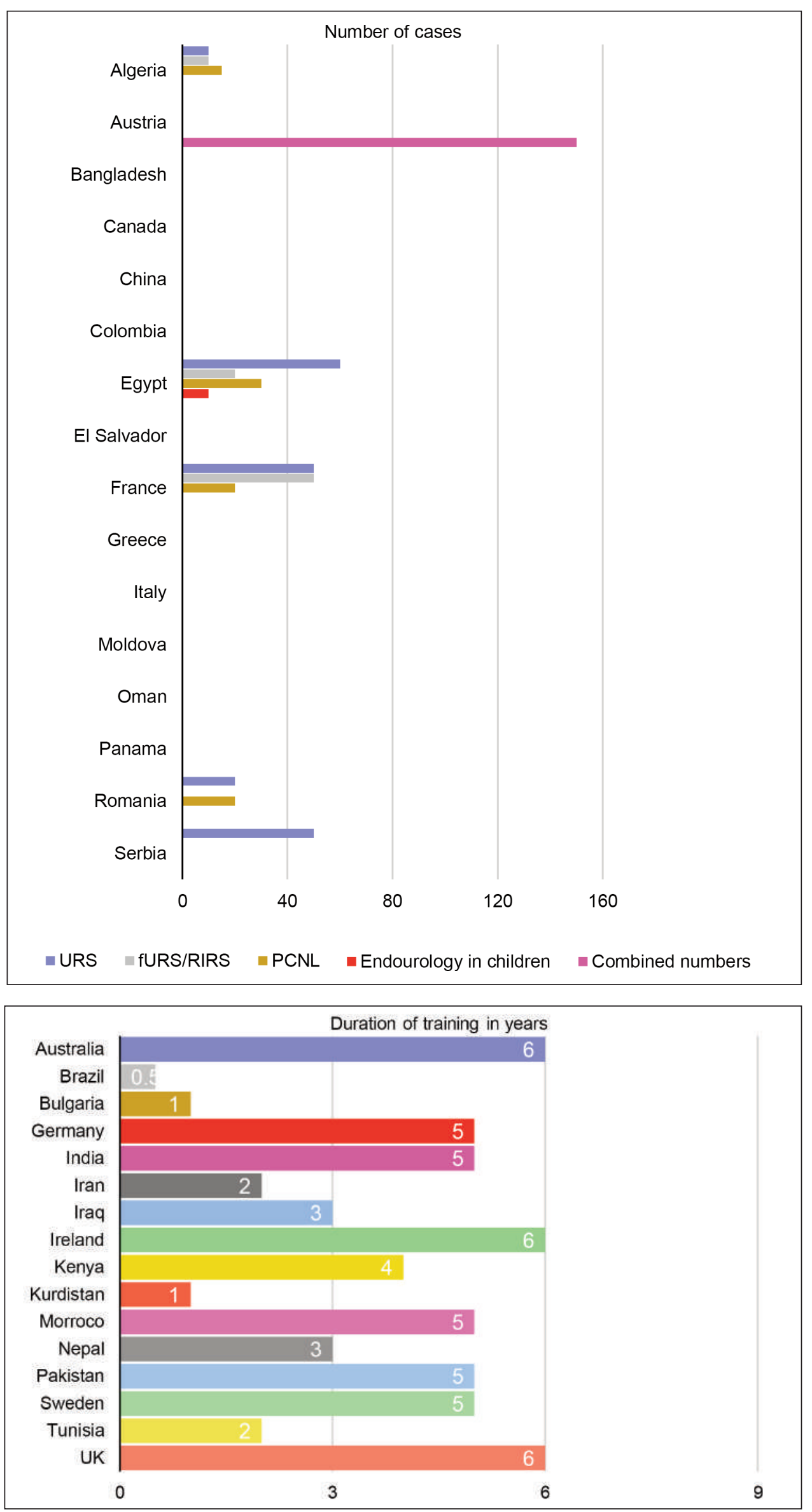

Figure 1.

Countries with no structured (endourology) training and indicative numbers of procedures (empty bars indicate no minimum number specified).

Figure 2.

ountries with structured (endourology) training programs: duration of training. 
Assessment of performance is via several methods including audit, general assessment, formal examination and viva with DOPS.

\section{Greece}

URS is a mandatory requirement with no specified indicative numbers. Completion of training is possible without further competence in endourology.

There is no provision of model training. Assessment of performance is via general assessment and DOPS.

\section{Italy}

There are no competence requirements for endourology. Indicative numbers are unspecified. There is no provision of model training. Assessment methods are not specified.

\section{Moldova}

Trainees are expected to gain independent level competence in URS for completion of training with unspecified indicative numbers. There is compulsory URS wet lab on animal models. The performance assessment method is unspecified.

\section{Oman}

Endourology is not a mandatory requirement for completion of training. There are no specified indicative numbers, model training or assessment methods.

\section{Panama}

URS, fURS/RIRS and PCNL are mandatory requirements for completion of training, however indicative numbers are not specified. Dry and wet labs are not available, and there is no specified method of assessment.

\section{Romania}

Although there is lack of structured endourology training, for completion of training it is mandatory to achieve competence in URS, fURS/RIRS and PCNL.

URS and PCNL are expected to be performed independently, fURS with trainer assistance. Twenty cases for URS are indicative. Dry and wet labs are not compulsory, and assessment of competency is not specified.

\section{Serbia}

URS and fURS/RIRS are mandatory requirements to complete training with 50 cases for URS as indicative number. Dry and wet labs for each of these procedures are accessible by trainees, but not compulsory.

Competency is assessed by general assessment.

\section{South Africa}

It is mandatory to achieve competence in endourology for completion of training. Trainees are required to gain competence in all procedures (URS, fURS/RIRS, PCNL and paediatric endourology). Level of competence is not specified with no indicative numbers. There are no dry or wet labs. Assessment of performance is via general assessment and DOPS.

\section{Spain}

Trainees are not required to gain competence in endourology to complete training. There are no specified indicative numbers, lab provisions or assessment methods.

\section{Syria}

Trainees are required to gain independent level competence in URS with exposure to PCNL and assistance in paediatric endourology. fURS training is not specified. There are no minimum case numbers and model training. Assessment of performance is not specified.

\section{United Arab Emirates}

There is no specific training program.

\section{Ukraine}

URS, fURS/RIRS and PCNL are mandatory for completion of training, however core competency, indicative numbers and lab provision are not specified. There is a general assessment of competency.

The following 16 countries do have a structured training program (Figure 3):

\section{Australia}

The training program runs for 6 years. It is mandatory to achieve competence in endourology for completion of training such as independent level competence in URS and fURS/RIRS. Performance of PCNL with assistance is a requirement. Paediatric endourology is learned at fellowship level. Indicative numbers include 100 URS, 75 fURS/RIRS, and 15 PCNL with no specified numbers for paediatric endourology. Dry and wet labs are not provisioned. Assessment of performance is via several methods including audit, general assessment, formal examination and viva with DOPS.

\section{Brazil}

A 6 month endourology program is in existence with mandatory expertise in URS. PCNL with assistance and exposure to fURS/RIRS is deemed satisfactory. Twelve URS and 6 PCNL are indicative for completion of training. There are no specified numbers for paediatric endourology. Lab training is not provisioned and there is no specified method of assessment of competence.

\section{Bulgaria}

An endourology program of 1-year duration exists with trainees expected to perform URS independently and PCNL with assistance. Exposure to fURS/RIRS is mandatory. Paediatric endourology is learned at fellowship level. Indicative numbers for each of these procedures are 50 URS, 10 each fURS/RIRS and PCNL. A dry lab is compulsory for each category, with the exception of endourology in children. Assessment of performance is via several methods including audit, general assessment, formal examination and viva with DOPS.

\section{Germany}

A 5-year urology training program is in place. Endourology training comprises of mandatory URS. fURS/RIRS, PCNL and endourology in children is not specified. Fifty URS procedures are indicative. Wet lab for URS is compulsory. Assessment of performance is via several methods.

5. India

Expertise in URS is mandatory as part of a 5-year uro- 


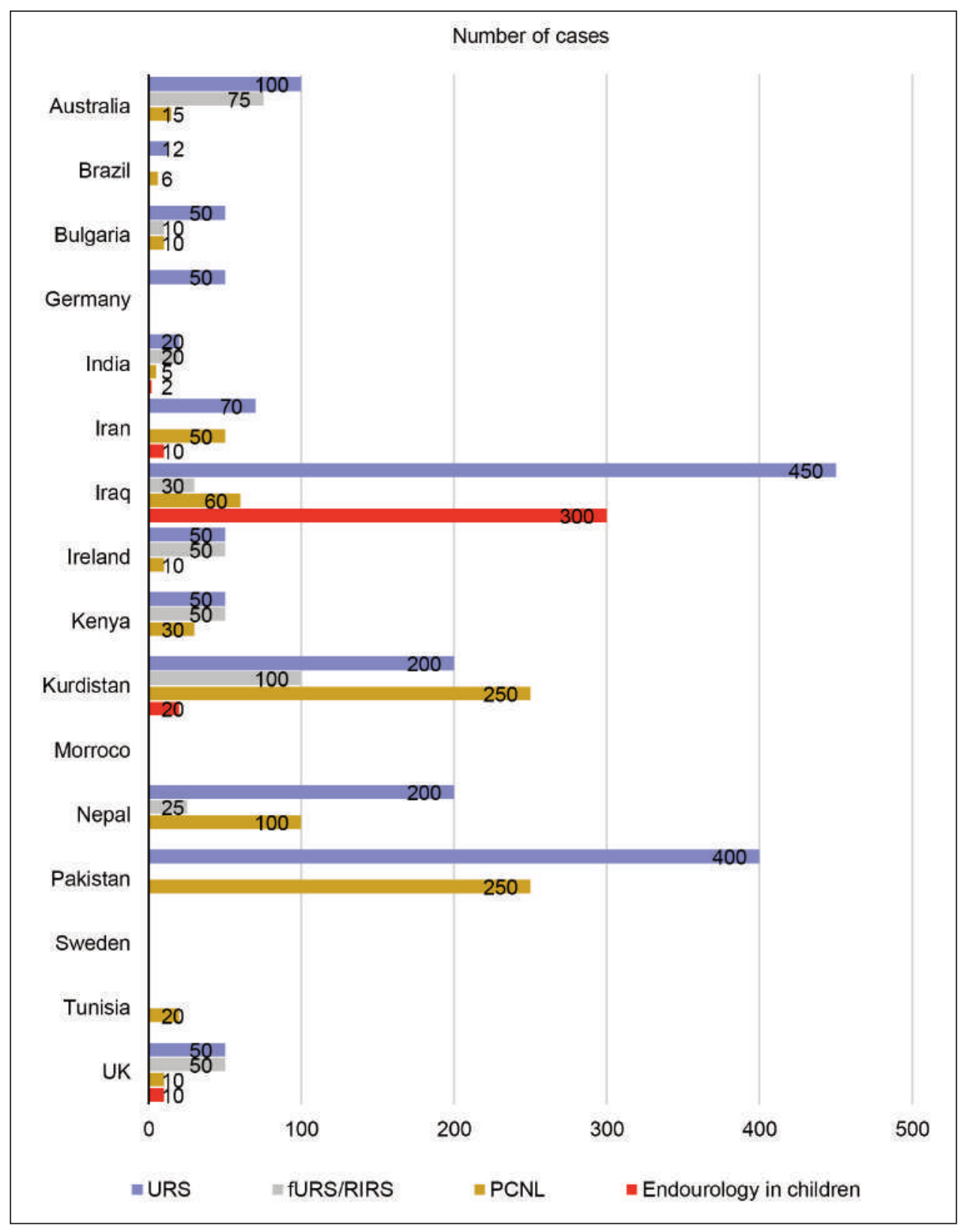

Figure 3.

Countries with structured endourology training and indicative numbers of procedures required (empty bars indicate no number specified).

logical training program. fURS/RIRS and PCNL are accepted to be performed with assistance. Paediatric endourology is not specified. Indicative numbers include 20 for URS, 20 for fURS/RIRS, 5 for PCNL and 2 in paediatric endourology.

There is a provision of dry lab for each of these procedures, albeit not compulsory. Assessment of performance is via general assessment.

\section{Iran}

An endourology program runs for 2 years with independent expertise in URS being mandatory. PCNL and paediatric endourology exposure is necessary, whereas fURS/RIRS is not specified. Seventy URS, 50 PCNL and 10 paediatric endourology cases are indicative. There is no provision of dry and wet labs. Assessment of performance is via several methods including audit, general assessment and DOPS.

\section{Iraq}

Endourology training for 3 years is mandatory, however trainees can finish training without gaining independent level competence in either of the endourology procedures with exception being URS. A minimum of 450 cases of URS, 30 of fURS/RIRS, 60 of PCNL and 300 of paediatric endourology are indicative. There is provision of dry and wet labs for each of these procedures which are compulsory. Assessment of performance is via several methods including audit, general assessment, formal examination and viva with DOPS.

\section{Ireland}

A 6-year training program exists, with a structured endourology training. URS, fURS/RIRS and PCNL are mandatory, with paediatric endourology learned at fellowship level. Trainees are required to gain independent level competence in URS and fURS/RIRS, with PCNL 
performed with trainer assistance. Indicative numbers 50 URS, 50 fURS, and 10 PCNL. There is no provision of lab training. Assessment of performance is via several methods including audit, general assessment, formal examination and viva with DOPS.

\section{Kenya}

URS, fURS/RIRS and PCNL are mandatory to achieve competence in endourology for completion of a 4-year training program. Paediatric endourology is performed at fellowship level hence not a requirement for completion of training. Trainees are expected to perform URS and fURS/RIRS independently, and PCNL with assistance. Fifty cases each for URS and fURS/RIRS, and 30 cases of PCNL are indicative. Lab is not provisioned. Assessment of performance is via several methods including audit, general assessment, formal examination and viva with DOPS.

\section{Kurdistan}

A one-year structured endourology training program makes it mandatory for trainees to be independently proficient to perform URS and fURS/RIRS, and PCNL to be performed with assistance. There is no specified paediatric endourology training. Two hundred cases for URS, 100 for fURS/RIRS, 250 cases of PCNL, and 20 paediatric endourology cases are indicative. There is no provision of lab training. Several methods such as general assessment, audit and DOPS are used for assessment.

\section{Morocco}

The training program comprises endourology training and runs for 5 years. Trainees are required to gain exposure to URS, fURS/RIRS and PCNL in order to complete their training. Endourological procedures in children are not a mandatory requirement. There are no specified indicative numbers, and no lab training. General assessment of performance exists to assess competency.

\section{Nepal}

It is mandatory to achieve competence in endourology for completion of training of a 3-year training. Trainees are required to gain independent level competence in URS, with fURS/RIRS and PCNL to be performed with trainer assistance. Endourological procedures in children are not a mandatory requirement. Two hundred cases for URS, 25 for fURS/RIRS, and 100 cases of PCNL are indicative, with no particularly specified numbers for paediatric endourology. There is no provision of lab training. Audit, general assessment, formal examination and viva are in place to assess competency of training.

\section{Pakistan}

A 5-year program exists with mandatory endourology training. Trainees are required to gain independent level competence in URS, with fURS/RIRS and PCNL performed with trainer assistance. Endourological procedures in children are not a mandatory requirement. Four hundred cases for URS and 250 cases of PCNL are indicative, with no particularly specified numbers for fURS/RIRS and paediatric endourology. There is no provision of dry and wet labs for each of these procedures. Several methods exist including audit, general assessment, formal examination and viva to assess competency.

\section{Sweden}

It is a mandatory requirement to achieve competence in endourology for completion of a 5-year training program. Trainees are required to gain independent level competence in URS, fURS/RIRS and PCNL in order to complete their training. Endourological procedures in children and indicative numbers are not specified. There are dry and wet labs for URS and fURS/RIRS, which are however not compulsory. Assessment is via DOPS.

\section{Tunisia}

A 2-year training program exists comprising of endourology training in URS and fURS/RIRS. PCNL is learned at fellowship level. Paediatric endourology is not specified. Trainees are required to gain independent level competence in URS. Twenty PCNL performed with assistance are indicative. A compulsory dry lab for URS and PCNL exists with optional fURS wet lab. Assessment is via audit, general assessment, formal examination and DOPS.

\section{United Kingdom}

The UK training program runs for 5 years with mandatory competence in URS, fURS/RIRS and PCNL. Endourological procedures in children are not a mandatory requirement. Trainees are required to perform URS and fURS/RIRS independently, with PCNL exposure, and no specified paediatric endourology. Fifty cases each for URS and fURS/RIRS, and 10 cases of PCNL, as well as 10 cases of paediatric endourology as indicative.

There is no compulsory lab training. Competency assessment is via several methods including audit, general assessment, formal examination, viva and DOPS.

\section{Discussion}

Our results have shown that there is a huge heterogeneity between training systems in various countries.

This has previously been confirmed by others $(5,6)$. Urological training, although embracing modern learning technologies in many countries, is far from ideal in most places. Inevitably, that will lead to huge differences in the training quality as well.

In Europe, there is a general lack of standardized training curricula. Great differences exist between training requirements in different countries. Trainees complain about a lack of confidence when performing major surgical procedures, non-compliance with European working hour regulations, a worrisome risk of burn-out and a negative impact on their work-life balance (6). Irish residents complain mainly about a lack of operative experience (7). In Spain, trainees find their training inadequate because of a lack of supervision, trainers completing their own training needs first, and a lack of operative experience (10). In Germany, $45 \%$ of trainees feel unprepared for their future roles. $85 \%$ complain about a lack in structured training, evaluations, and transparency. Another complaint is economic constraints during training (8). Throughout South America, training, accreditation and re-certification are highly heterogenous and far 
from being standardized. In addition, academic activities are not properly valued (5).

Turkish residents report a lack of surgical exposure, and of encouragement for any academic activities (11). In Tunisia, most trainees in urology were dissatisfied with their training (9).

Training is further compromised by reduced working hours for training as well as an increasing threat of litigation (12).

All these studies confirm that there is a dire need to improve training quality in urology internationally. Not only may patient safety be compromised, but even the trainees themselves will face a future that they do not feel ready for, and that they are not adequately trained for. So how could one achieve a meaningful improvement? It appears that a well-structured training approach is key to ensure a surgeon's professional growth in the safest way for the patients (4).

Structured training is in place in some countries who may serve as a model for others. Structuring the training may start with the right candidate selection. A surgeon needs compassion, communication skills, and should be perceptive and dedicated, besides manually skilled (2). Structuring this crucial initial step of training, recruitment should be at least regional, if not national. Candidates must undergo a validated assessment by objective, well-trained and experienced assessors. The process should be overseen by national authorities such as colleges or deaneries. This way each candidate will have the same chances and will undergo the same assessment, decreasing the chance of subjective bias. The UK system may serve here as an example (13).

The next step to structure would be the training program itself. Most modern training programs have already moved from a "see one, do one, teach one" approach to a structured learning - at least in minimally invasive treatment options -, and from e-learning to skills labs and modulated training settings (14). A structured training program will encompass a better definition of training goals and skills, specialization, structured evaluation, standardization of exams and include research (8). Simulation-based training can indeed address many concerns of the old apprenticeship model, such as patient safety, efficient acquisition of complex surgical skills, overcoming the learning curve, and cost-effectiveness (4, 15). Improved structured training should include structured scheduling of activities, use of peer training, elearning, access to simulation training on high fidelity models and/ or animals, trainee information on all available resources, effective tutoring, research, and evidence based practice learning $(2,9,16,17)$.

A consensus has been reached on markers defining the quality of a surgical training program (18):

- Trainer - trainee relationship

- Operative exposure

- Supervision

- Feed back

- Structures and organization of training

- Structured teaching programs

No training is effective without assessment of the competency and proficiency achieved by the trainee.
However, assessments are often perceived as haphazard, subjective and non-transparent $(5,8)$.

In structured simulation training programs, the most commonly used tools for objective assessment are (15):

- Technical skills assessment

- global rating scale of performance rating scores

- questionnaires and post-training surveys

- structured assessment by use of video recording

- motion tracking software.

Another established, effective and valuable tool in surgical training assessment is the Direct Observation of Procedural Skills (DOPS) $(19,20)$.

In any case, trainee assessment has to move away from the mere measure of the number of surgical procedures to mediation of competencies and skills as markers of competency $(21,22)$.

A consensus statement has been reached on the quality markers of training assessment (18):

- trainee feedback

- trainer feedback

- timetable structure

- trainee improvement.

However, there are also barriers to effective training assessment which we must bear in mind. These are uncertainty on what to document, concern of a negative impact on faculty popularity amongst trainees, lack of clear standards, and lack of effective remediation options (23)

According with the mission of Urology for emerging countries (U-merge), the authors looked at a wide array of urological training in various countries. It is notable that structured training programs do not only exist in developed countries, and old-fashioned apprenticeship models do still prevail in some developed countries although modern learning options are readily available there, albeit not implemented.

Especially but not only in the developing world, urological training is marred by inconsistency, lack of structure, and lack of focus on research and evidence-based practice (2). This is where an international and/or global training approach comes into play. More affluent countries could afford to help less fortunate countries to establish sustainable, capacity-building educational collaborations that are essential to address the global burden of global disease. International collaboration can lead the way towards competency-based training, assessment of technical skills by international standards, longterm trainer proficiency, and community-specific quality initiatives (24). Established tools for this purpose are an online curriculum, visiting educator trips, expert surgeon involvement, trainee competency tracking and identification of local outreach partners (25).

However, any collaboration towards standardized and structured training needs to be responsible, meaning responding to locally identified needs, training projects according to local contexts, and a general working towards self-sufficiency of the trainees (26).

Our results have shown a huge heterogeneity in quality urology training between countries and within continents. In systems without national structure of training it 
can be assumed that such differences exist even between hospitals/training institutions. There is no doubt in times of globalization with resident and doctor migration and exchanges that training needs structure and standardization. The still huge gap in developing countries to catch up and be able to afford latest surgical and learning technologies need to be addressed with the help of responsible outreach programs.

There is ample literature on the requirements of structured training programs and assessments, and we have tried to briefly outline the key points in this paper.

\section{References}

1. Campain NJ, Kailavasan M, Chlawe M, et al. An Evaluation of the role of simulation training for teaching surgical skills in subsaharan Africa. World J Surg. 2018, 42:923-929.

2. Ather MH, Siddiqui T. Urology training in the developing world: The trainer's perspective. Arab J Urol. 2013. http://dx.doi.org/ 10.1016/j.aju.2013.07.001

3. Anderson JT. Assessments and skills improvement for endoscopists. Best Pract Res Clin Gastroenterol. 2016, 30:453-471.

4. Sarikaya S, Meneses AD, Cacciamani GE, Rivas JG. Future of urology training. Arch Esp Urol. 2018; 71:158-163.

5. Angulo JC, Figueroa C, Gomez R, et al. Current status of urological training in South America. Arch Esp Urol. 2018; 71:23-33.

6. Carrion DM, Gomez Rivas J, Esperto F, et al. Current status of urological training in Europe. Arch Esp Urol. 2018; 71:11-17.

7. O'Sullivan KE, Byrne KS, Walsh TN. Basic surgical training in Ireland: the impact of operative experience, training, program allocation and mentorship on trainee satisfaction. Ir J Med Sci. 2013; 182:687-692.

8. Struck JP, Cebulla A, Ralla B, Koenig J. Structured training curriculum for urological residents: chances and limits. Urologe A. 2019; 58:109-113

9. Naouar S, Binous MY, Braiek S, El Kamel R. Training of Tunisian future urologists: how to improve it. Tunis Med. 2018; 96:401-404.

10. Soria F, Villacampa F, Serrano A, et al. Training program in endourological surgery. Future perspectives. Arch Esp Urol. 71:89-96.

11. Sarikaya S. Needs, realities and expectations for urology training: Questionnaire-based study. Arch Esp Urol. 2018; 71:18-22.

12. Lovegrove CE, Abe T, Aydin A, et al. Simulation training in upper tract endourology: myth or reality? Minerva Urol Nefrol. 2017; 69:579-588.

13. NHS health education England: Training and development (urology) https://www.healthcareers.nhs.uk/explore-roles/doctors/ roles-doctors/surgery/urology/training-and-development. Accessed 29.11.2019.

14. Van der Poel H, Brinkman W, van Cleynenbreugel B, et al. Training in minimally invasive surgery in urology: European Association of Urology/ International Consultation of Urological Diseases consultation. BJU Int. 2016; 117:515-530.

15. Atesok K, Satava RM, Marsh JL, Hurwitz SR. Measuring surgical skills in simulation-based training. J Am Acad Orthp Surg. 2017; 25:665-672.

16. De Vries AH, van Luijk SJ, Scherpbier AJ, et al. High acceptability of a newly developed urological practical skills training program. BMC Urol. 2015; 15:93.
17. Schiavina R, Borghesi M, Dababneh $H$, et al. The impact of a structured intensive modular training in the learning curve of robot assisted radical prostatectomy. Arch Ital Urol Androl. 2018; 90:1-7.

18. Siau K, Dunckley P, Valori R, et al. Joint Advisory Group on Gastrointestinal Endoscopy. Changes in scoring of direct observation of procedural skills (DOPS) forms and the impact on competence assessment. Endoscopy. 2018; 50:770-778.

19. Khanghahi M, Azar EF. Direct observation of procedural skills (DOPS) evaluation method: Systematic review of evidence. Med J Islam Repub Iran. 2018; 32:45.

20. Heidenreich A, Salem J, Paffenholz P, Pfister D. Interdisciplinary education in urology: innovations for better training. Urologe A. 2019; 58:870-876.

21. Forbes N, Mohamed R, Raman M. Learning curve for endoscopy training: Is it all about numbers? Best Pract Res Clin Gastroenterol. 2016; 30:349-356.

22. Singh P, Aggarwal R, Zevin B, et al. A global Delphi consensus study on defining and measuring quality in surgical training. J Am Coll Surg. 2014; 219:346-353.

23. Sanfey H. Assessment of surgical training. Surgeon. 2014; 12:350-356

24.Wagner JP, Schroeder AD, Espinoza JC, et al. Global outreach using a systematic, competency-based training paradigm for inguinal hernioplasty. JAMA Surg. 2017; 152:66-73.

25. Sue GR, CovingtonWC, Chang J. The ReSurg global training program: a model for surgical training and capacity building in global reconstructive surgery. Ann Plast Surg. 2018; 81:250-256.

26. Macpherson L, Collins M. Training responsibly to improve global surgical and anaesthesia capacity through institutional health partnerships: a case study. Trop Doct. 2017; 47:73-77.

\section{Correspondence}

Asad Ullah Aslam, MD

asadullahaslam@gmail.com

Dept. of Urology, Letterkenny University Hospital, Saolta Healthcare Group (Ireland)

Joseph Philipraj, MD

josephphilipraj@gmail.com

Department of Urology, Mahatma Ghandi Medical College \& Research Institute Sri Balaji Vidyapeeth, Pondicherry (India)

Sayed Jaffrey, MD jaffry@urology.ie

Dept. of Urology, University College Hospital, Galway Clinic and Bons Secours Hospital, Galway (Ireland)

Noor Buchholz, MD (Corresponding Author)

scientific-office@u-merge.com

U-merge scientific office

Athens/Greece 